\title{
Acute epiglottitis in the adult: is intubation mandatory?
}

Edward Crosby BSc MD FRCPC, Dennis Reid MB ChB FFARCS FRCPC
Acute epiglottitis ( $A E$ ) in the adult results in inflammation of the supraglottic structures and carries the potential for complete airway obstruction. There is disagreement in the medical literature as to the appropriate management of the airway in the adult with AE. Some authors advocate intubation in all patients while others propose more selective intervention, intubating the trachea only in those patients presenting with airway compromise. We reviewed our institutional experience with 21 patients over the last seven years admitted with a proven diagnosis of $A E$. Six patients presented with respiratory distress, three in severe distress with symptoms and signs of upper airway obstruction. The three patients in severe distress were taken to the operating room, in two the tracheas were intubated and one underwent tracheostomy after failed intubation. All other patients were monitored but their tracheas were not intubated. The majority of the patients were monitored for $24 \mathrm{hr}$ in the ICU before transfer to wards. No patient initially monitored required tracheal intubation for progression of disease. There were no deaths. Recommendations for the care of the airway in the adult with $A E$ based on our experience and a review of approximately 1000 cases reported in the last ten years are presented. It is our opinion that adults presenting without respiratory symptoms may be safely monitored in an intensive care setting given that provision is made for tracheal intubation or tracheostomy should respiratory distress become evident.

L'épiglottite aiguë de l'adulte (AE) est le résultat d'une inflammation des structures supraglottiques et présente un risque potentiel d'obstruction complète des voies aériennes. On note un désaccord dans la littérature médicale concernant la conduite optimale à tenir concernant les voies aériennes chez $l$ 'adulte atteint d'épiglottite aiguë. Certains auteurs conseillent

\section{Key words}

COMPLICATIONS: epiglottitis;

EQUIPMENT: tracheostomy;

INTUBATION: tracheal.

From the Department of Anaesthesia, Ottawa General Hospital, Module A-11, University of Ottawa, 501 Smyth Road, Ottawa, Ontario K1H 8L6.

Address correspondence to: Dr. E. Crosby. Accepted for publication 28th May, 1991. l'intubation chez tous les patients alors que d'autres proposent une intervention plus sélective où l'intubation serait indiquée seulement si les voies aériennes sont compromises. On a revu notre expérience dans notre institution avec 21 patients admis durant les sept dernières années avec un diagnostic confirmé d'épiglottite aiguë. Six patients ont été admis en détresse respiratoire, trois en détresse respiratoire sévère avec des signes et symptômes d'obstruction des voies aériennes hautes. Les trois patients ayant une détresse respiratoire sévère furent amenés en salle d'opération où deux ont été intubés et un a subi une trachéostomie après echec de l'intubation. Tous les autres patients furent surveillés mais leur trachée n'a pas été intubée. La majorité des patients furent surveillés pour 24 heures aux soins intensifs ayant le transfert aux étages. Aucun patient initialement surveillé n' a requis l' intubation trachéale pour une aggravation de sa maladie. Il n'y a eu aucun décès. Les recommendations pour la conduite et le soin des voies aériennes chez l'adulte atteint d'épiglottite aiguë en se basant sur notre expérience et une revue d' approximativement 1000 cas rapportés dans les dix dernières années sont présentées. Selon nous, les adultes n'ayant pas de symptôme respiratoire peuvent être surveillés avec sécurité aux soins intensifs tout en ayant à notre disposition la possibilité d'intubation ou de trachéotomie si la détresse respiratoire devient évidente.

Acute epiglottitis (AE) in the adult is a serious infection of the supraglottic structures which carries the potential for lethal, total airway obstruction. Following correct diagnosis and implementation of antibiotic therapy, a rapid clinical resolution is common. There is controversy whether it is necessary to intubate the tracheas of all adults with a diagnosis of $\mathrm{AE}$ although there is no dispute that this is appropriate management in all children with $\mathrm{AE}{ }^{1}$ The proponents of intubation argue that sudden and lethal airway obstruction can occur and the airway should be secured. $^{2-4}$ The contrary position is that the airway in most adults with $\mathrm{AE}$ is not jeopardized, that tracheal intubation is not usually required and that sudden complete obstruction, without preceding symptoms or signs of respiratory distress, is not common. ${ }^{5-7}$

We reviewed and describe our experience with 21 patients with AE, over a seven-year period, and suggest a protocol for the airway management of the adult patient with AE. 


\section{Methods}

The charts of all patients with the diagnosis of $\mathrm{AE}$ admitted to our institution between January, 1983 and December, 1989, were retrieved and analyzed. The clinical diagnosis was confirmed in all patients by indirect (mirror) or direct (fibreoptic nasolaryngoscope or laryngoscope) examination. The following data were recorded from the chart: age, sex, nature and duration of prodromal illness, contact with a physician in the $24 \mathrm{hr}$ before presentation, symptoms at the time of presentation, specifically sore throat, dysphagia or odynophagia, voice change and descriptor used, signs and symptoms of respiratory distress including tachypnoea, stridor, cyanosis, orthopnoea, dyspnoea, impending or actual respiratory arrest, and temperature. The lateral cervical $x$-rays were retrieved and measurements of the epiglottitis and the aryepiglottic folds were made and compared with previously established values for adult epiglottitis ${ }^{8}$ The results of the oropharyngeal tongue blade examination and the indirect (mirror) or direct (nasolaryngoscope, laryngoscope) were recorded. The details of patient management (observation, intubation or tracheostomy) and the recorded indications for the mode of management were noted as were the complications related to the mode chosen.

\section{Results}

\section{Patient assessment}

\section{PRESENTING SYMPTOMS}

Twenty-one patients were admitted to our institution during the period of the review with the diagnosis of $\mathrm{AE}$ supported by both clinical findings and $x$-ray. Sixteen $(76 \%)$ of the patients were male, five female and the average age was $36.7 \mathrm{yr}$ (range 16-68 yr). Six patients (29\%) had a prodromal upper respiratory tract infection, lasting from one to seven days before the onset of the presenting symptoms. The presenting symptoms are shown in Table I. Sore throat was the only uniform symptom, being present in all patients, was severe in most and represented the major presenting complaint in 16 patients $(76 \%)$. Difficulty with swallowing was a common presenting complaint, present in 20 patients (95\%). A voice change was remarked upon by 12 patients $(57 \%)$, with hoarse (eight patients) and muffled (four patients) being the descriptors used to describe the change. Sixteen patients $(76 \%)$ had an elevated temperature. Mild respiratory distress was noted in three patients $(14 \%)$ at the time of presentation; in two patients orthopnoea was the main complaint and in one dyspnoea. Severe respiratory distress was present in three patients at the time of presentation and was characterized by tachypnoea greater than 30 breaths per minute (three patients), stridor (two
TABLE I Presenting symptoms

\begin{tabular}{lr}
\hline Symptom & \multicolumn{2}{c}{ Number of patients $(\%)$} \\
\hline Sore throat & $21(100)$ \\
Odynophagia & $17(76)$ \\
Dysphagia & $3(14)$ \\
Voice change & $12(57)$ \\
Temperature $\geq 37.9^{\circ} \mathrm{C}$ & $16(76)$ \\
Respiratory distress & $6(29)$ \\
\hline
\end{tabular}

patients), and cyanosis (one patient). Airway obstruction was either impending (two patients) or present (one patient) at the time of presentation. The symptoms had persisted from three hours to five days with most (19 patients) reporting symptoms of two days or less. Six patients (29\%) had seen a physician in the $24 \mathrm{hr}$ before presentation (missed diagnosis).

\section{Airway examination}

Oropharyngeal examination with a tongue blade revealed mild to moderate pharyngitis in 17 patients, exudative pharyngitis in one, was normal in one and was not carried out in two patients. One of these patients was a referral from a peripheral hospital with a diagnosis of $\mathrm{AE}$, the second patient was in extremis at the time of presentation. Epiglottitis (18 patients) or supraglottitis (two patients) was observed in all (20) patients examined with either a mirror or nasolaryngoscope. Three patients were examined in the operating room under direct vision with an oral laryngoscope, after induction of general anaesthesia, including the patient in extremis.

\section{Patient management}

Eighteen patients (86\%) were observed, without tracheal intubation, 13 in the intensive care unit, one in the emergency room and four on patient wards. The patients observed on the wards were admitted between 1983 and 1985. The duration of the ICU observation period was 24 $\mathrm{hr}$ for 11 patients and $72 \mathrm{hr}$ for two. Patients observed included two who had complained of orthopnoea on admission and one who was dyspnoeic. This latter patient was pancytopaenic following chemotherapy for lympho$\mathrm{ma}$ and there was some reluctance to intervene surgically on her airway. Intervention for airway support because of a deterioration in status was not necessary in any patient who was initially observed. Rather, the two patients who had been orthopnoeic quickly became symptom-free after initiation of antibiotic therapy. The patient who presented with dyspnoea remained symptomatic for $36 \mathrm{hr}$ before subjective clinical improvement was noted.

The three patients who had severe respiratory distress (dyspnoea, tachypnoea $>30 \mathrm{bpm}$, stridor or cyanosis) at the time of presentation to hospital were taken to the 
operating room and, with an otolaryngologist in attendance, inhalational (two patients) or modified inhalational induction (one patient) of general anaesthesia was carried out and tracheal intubation was attempted. One trachea was then intubated easily, in one patient the airway was described as "difficult" although the intubation was uneventful, and in one patient a failed intubation led to an emergency tracheostomy. These latter two patients were found to have pulmonary oedema after intubation, were treated with furosemide and positive pressure ventilation with positive end-expiratory pressure and the oedema resolved. The patient with the "difficult" airway was returned to the operating room on the third day because of persistent fever and bilateral peritonsillar and epiglottic abscesses were drained. A prompt resolution of the patient's toxic state followed and his trachea was extubated the following day.

There were no deaths in the series. The duration of hospitalization averaged 4.7 days in the entire group, 4.3 days in the observed group and seven days in the intubated group. The patient with lymphoma had the longest hospital stay of 11 days.

\section{Discussion}

Acute epiglottitis, long recognized in children was, until recently, thought to be rare in adults. However, in three recent reports adults comprised $35-53 \%$ of the patients in the series. ${ }^{7,9,10}$ The incidence of $\mathrm{AE}$ in the adult population has been estimated at between $0.97-1.8$ per 100,000 population. ${ }^{4,7,10}$ Mortality rates as high as $50 \%$ have been reported in the past but have decreased over the last $20 \mathrm{yr}$. Compiling the series reported since 1980 yields 904 patients with ten deaths, a mortality rate of $1.1 \% .^{4-7,9-21}$ Mortality is increased in those patients who present with respiratory distress and Khilanani, in a separate series of 118 adult $\mathrm{AE}$ patients presenting with respiratory distress, reported a mortality rate of $17.6 \% .^{22}$

Most adults with epiglottitis present with sore throat. Respiratory distress is a less common feature of the disease in adults compared with paediatric $\mathrm{AE}$, being documented in 25-69\% of adults (weighted mean $31 \%)^{1,4,6,7,11,13,16,19,20}$ Sore throat was present in all of our patients whereas respiratory distress was limited to less than one-third. Oropharyngeal examination with a tongue blade and light appears to be well tolerated in adults with $\mathrm{AE}$ and does not induce respiratory distress, despite the commonly expressed concern that sudden airway obstruction may occur as a result of such examination. ${ }^{23}$ Oropharyngeal examination was carried out in 19 of our patients, was apparently well-tolerated and was either normal (one patient) or revealed only mild to moderate pharyngitis in most (18 patients).

Visual examination of the epiglottitis is necessary to
TABLE II Acute epiglottitis: the Friedman classification

\begin{tabular}{llll}
\hline Stage I & Stage II & Stage III & Stage IV \\
\hline $\begin{array}{llll}\text { No respiratory } \\
\text { complaints }\end{array}$ & $\begin{array}{l}\text { Subjective } \\
\text { respiratory } \\
\text { complaint }\end{array}$ & $\begin{array}{l}\text { Moderate } \\
\text { respiratory } \\
\text { distress }\end{array}$ & $\begin{array}{l}\text { Severe } \\
\text { respiratory } \\
\text { distress }\end{array}$ \\
$\begin{array}{llll}\text { Respiratory rate } \\
\leq 20\end{array}$ & $\begin{array}{ll}\text { Respiratory rate } \\
\text { Stridor, } \\
\text { retractions, } \\
\text { perioral } \\
\text { cyanosis }\end{array}$ & $\begin{array}{l}\text { Stridor, } \\
\text { retractions, } \\
\text { cyanosis, } \\
\text { delerium, } \\
\text { decreased } \\
\text { consciousness }\end{array}$ \\
& $>20$ & $\begin{array}{l}\text { Respiratory } \\
\text { rate }>30\end{array}$ & Respiratory \\
& & arrest
\end{tabular}

From: Friedman $M$, Toriumi DM, Grybauskas V, Applebaum EL. A plea for uniformity in the staging and management of acute epiglottitis. Ear, Nose Throat J 1988; 67: 873-80.

confirm or rule out the diagnosis of AE. Indirect (mirror) laryngoscopy has been used in the past and more recently the fibreoptic nasolaryngoscope has been employed. The examinations appear to be well tolerated and there is some evidence that the nasolaryngoscope results in less oropharyngeal discomfort than the mirror. The positive findings on visual examination reflect a generalized supraglottitis, rather than inflammation affecting the epiglottis alone. ${ }^{2}$

\section{Airway management}

The appropriate management of the airway in the adult patient with $\mathrm{AE}$ is controversial. Recent reports in the anaesthetic literature advocate tracheal intubation or tracheostomy in all adults with $\mathrm{AE} .^{2,3,23,24}$ Other authors recommend an artificial airway only in those patients presenting with respiratory distress. ${ }^{5-7,9,11,13-17,19,20}$ In these series reporting on 812 patients, the weighted average intubation rate was $21 \%$ and the mortality rate was $0.6 \%$. Unfortunately, details of patient assessment, categorization of the degree of respiratory distress and criteria for intubation are not provided in most of these series. Authors advocating selective intubation argue that most adult patients do not present with respiratory distress and that acute deterioration and respiratory arrest in a monitored patient is rare. Instances of "sudden respiratory arrest" have occurred in patients who presented in respiratory distress and were admitted without close observation. ${ }^{3,18,24}$ Friedman has defined four stages of adult $\mathrm{AE}$ and maintains that, if carefully observed, patients move through the stages in sequence and that sudden respiratory arrest does not occur in patients with no previous evidence of airway compromise ${ }^{21}$ (Table II).

Pulmonary oedema following intubation has been reported in both adults and children with $\mathrm{AE} .^{23,25}$ Normal 
TABLE III Acute epiglottitis: airway management

1 No respiratory complaints (Friedman Stage I)

(a) Monitoring in ICU

(b) Humidified oxygen

(c) Intravenous antibiotics

(d) Intubation/tracheostomy kit immediately available

2 Mild to moderate respiratory distress (Friedman Stage II, III)

(a) Transport to operating room

(b) Otolaryngologist standing by, setup for tracheostomy

(c) Attempt inhalational, modified inhalational induction If airway obstructs options include:

(i) attempt intubation

(ii) establish surgical airway

(iii) needle cricothyrotomy, oxygenate, then perform intubation, retrograde intubation or tracheostomy

3 Severe respiratory distress, impending arrest (Friedman Stage IV)

(a) Immediate intubation, cricothyrotomy or tracheostomy in the emergency room

pulmonary artery pressures were measured in the adult report. Both adults with pulmonary oedema died and the suggestion was that the pulmonary capillary leak was a result of overwhelming sepsis, profound hypoxia or extreme negative intrathoracic pressure. ${ }^{23}$ Two of our patients were found to be in pulmonary oedema after difficult intubations. The oedema resolved quickly and the subsequent clinical course of both patients suggested that negative intrathoracic pressure was the cause of the capillary leak.

\section{Recommendations for management}

Any adult presenting with painful dysphagia should be considered to have epiglottitis until proven otherwise. The diagnosis must be confirmed or ruled out on the basis of visual examination of the supraglottic structures. A protocol for the airway management of the adult with $\mathrm{AE}$ is provided in Table III. It is our opinion that an adult with a diagnosis of $\mathrm{AE}$ experiencing no signs or symptoms of respiratory distress (Friedman Stage I) can be safely monitored in an intensive care unit. Humidified oxygen should be provided and antibiotic therapy commenced after appropriate cultures are obtained. ${ }^{2,11}$ Equipment for emergency intubation and tracheostomy should be at the patient's bedside and experienced personnel available. Should the patient develop new signs or symptoms of respiratory distress an artificial airway should be established. There is no role for racemic epinephrine or helium-oxygen mixtures in these patients. Patients who initially present with respiratory distress or develop signs or symptoms of airway compromise after hospital admission (Friedman Stage II-III) should undergo intubation or tracheostomy. Complete airway obstruction occurs in
TABLE IV Acute epiglottitis: Criteria for Extubation

1 Normal temperature, resolution of systemic toxicity

2 Normal chest $x$-ray

3 Patient able to breathe around occluded endotracheal or tracheostomy tube with cuff deflated

4 Visual examination of supraglottic structures indicates decreased oedema and inflammation

$18.3 \%$ of these patients, may develop rapidly and results in a mortality rate of $17.6 \% .^{22}$ The trachea should be intubated under controlled conditions in the operating room with an otolaryngologist standing by and a setup for a surgical airway available. There were three patients in our series who fitted Friedman Stage II, but their tracheas were not intubated and they did well. Nevertheless, given the considerable reported incidence of complete airway obstruction and mortality in these patients, ${ }^{22}$ it would appear prudent to secure the airway with tracheal intubation or tracheostomy. Patients presenting in impending or actual respiratory arrest (Friedman Stage IV) should undergo immediate tracheal intubation, cricothyrotomy or tracheostomy in the emergency room.

For tracheal intubation, an inhalational induction has been recommended and a slow and difficult induction should be anticipated. Airway obstruction may worsen or become complete either with excitement or as the patient becomes anaesthetized. Should this occur, a number of options exist including an immediate attempt at orotracheal intubation, establishment of a surgical airway or temporizing the situation with a needle cricothyrotomy and then performing orotracheal intubation, retrograde intubation or establishing a surgical airway.

In adults, the toxic state quickly defervesces with antibiotic therapy. Continued fever suggests abscess development and mandates careful examination with incision and drainage if present. Nonintubated patients should be reassessed at $24 \mathrm{hr}$ and if the clinical picture is resolved and the swelling is reduced on visual examination, they may be discharged to the ward. Criteria for extubation are summarized in Table IV. Barring complications extubation will be performed in most patients within 2-3 days.

We have reported our experience with 21 adults with AE. Respiratory distress was present in $29 \%$ and was severe in $15 \%$. All patients presenting with severe respiratory distress had artificial airways established. The remainder of the patients were monitored and over the last five years all monitoring took place in an ICU. There is disagreement between recent management recommendations appearing in the anaesthetic and the otolaryngology literature. The anaesthetic literature supports mandatory intubation of all adults with acute AE while the otolaryn- 
gology literature recommends more selective intervention in those patients with respiratory distress. It would appear that only about one-quarter of adult patients require tracheal intubation, and those patients requiring airway support can be differentiated from the others on the basis of respiratory symptoms. It is both prudent and safe to monitor adults with $\mathrm{AE}$ but without signs or symptoms of airway compromise in an ICU setting until there is evidence of resolution of the airway inflammation. Because the literature appears to document an increased incidence of airway obstruction in AE patients with respiratory symptoms and it is not possible to predict which patients with respiratory symptoms will progress to complete airway obstruction, it is recommended that adults with $\mathrm{AE}$ presenting with respiratory symptoms undergo tracheal intubation or tracheostomy.

\section{Acknowledgements}

The authors would like to thank Health Records Analyst Lori Greenberg for her assistance in assembling the patient data and to Sylvie Paquette for typing the manuscript.

\section{References}

1 Fitz-James 1 . Epiglottitis in children and adults. Anesthesiology Report 1990; 2: 339-46.

2 Baxter FJ, Dunn GL. Acute epiglottitis in adults. Can J Anaesth 1988; 35: 428-35.

3 Bishop MJ. Epiglottitis in the adult. Anesthesiology 1981; 55: 701-2.

4 Mayosmith MF, Hirsch PJ, Wodzinski SF, Schiffman $F J$. Acute epiglottitis in adults. An eight-year experience in Rhode Island. N Engl J Med 1986; 314: 1133-9.

5 Baker AS, Eavey RD. Adult supraglottitis (epiglottitis). N Engl J Med 1986; 314: 1185-6.

6 Arndal $H$, Andreassen $U K$. Acute epiglottitis in children and adults. Nasctracheal intubation, tracheostomy or careful observation? Current status in Scandinavia. J Laryngol Otol 1988; 102: 1012-6.

7 Murrage KJ, Janzen VD, Ruby RR. Epiglottitis: adult and pediatric comparisons. J Otolaryngol 1988; 17: 194-8.

8 Schumaker HM, Doris PE, Birnbaum G. Radiographic parameters in adult epiglottitis. Ann Emerg Med 1984; 13: 588-90.

9 Andreassen UK, Husum B, Tos $M$, Leth $N$. Acute epiglottitis in adults. A management protocol based on a 17-year material. Acta Anaesthesiol Scand 1984; 28 : 155-7.

10 Trollfors $B$, Nylen $O$, Strangert $K$. Acute epglottitis in children and adults in Sweden 1981-3. Arch Dis Child 1990; 65: 491-4.
11 Chaisson RE. Epiglottitis in adults. In: Sande MA, Hudson LD, Root RK (Eds.). Respiratory Infections. New York: Churchill Livingstone, 1986; 127-37.

12 Phelan DM, Love JB. Adult epiglottitis. Is there a role for the fiberoptic bronchoscope? Chest 1984; 86: 783-4.

13 Ossoff RH, Wolff AP, Ballenger $J J$. Acute epiglottitis in adults: experience with fifteen cases. Laryngoscope 1980; 90: 1155-61.

14 Shih L, Hawkins DB, Stanley RB. Acute epiglottits in adults. A review of 48 cases. Ann Otol Rhinol Laryngol 1988; 97: 527-9.

15 Walker PJ, Dwyer DE, Curotta JH. Adult epiglottitis. Med J Austral 1988; 148: 309-10.

16 Deeb ZE, Yenson AC, DeFries HO. Acute epiglottitis in the adult. Laryngoscope 1985; 95: 289-91.

17 Warshawski J, Havas TE, McShane DP, Gullane PJ. Adult epiglottitis. J Otolaryngol 1986; 15: 362-5.

18 Hanna GS. Acute supraglottic laryngitis in adults. J Laryngol Otol 1986; 100: 971-5.

19 Mustoe T, Strome $M$. Adult epiglottitis. Am J Otolaryngol 1983; 4: 393-9.

20 Black MJ, Harbour J, Remsen KA, Baxter JD. Acute epiglottitis in adults. J Otolaryngol 1981; 10: 23-7.

21 Friedman $M$, Toriumi DM, Grybauskas V, Applebaum $E L$. A plea for uniformity in the staging and management of adult epiglottitis. Ear, Nose, Throat J 1988; 67: 873-80.

22 Khilanani $U$, Khatib $R$. Acute epiglottitis in adults. Am J Med Sci 1984; 287: 65-70.

23 Warner JA, Finlay WE. Fulminating epiglottitis in adults. Anaesthesia 1985; 40: 348-52.

24 Morgenstein KM, Abramson AL. Acute epiglottitis in adults. Laryngoscope 1971; 81: 1066-73.

25 Soliman $M G$, Richer $P$. Epiglottitis and pulmonary oedema in children. Can Anasth Soc J 1978; 25: 270-5. 